\title{
An electrochemical quartz crystal microbalance study of poly(acrylonitrile) deposition initiated by electrogenerated superoxide
}

\author{
Matthew J. Lacey ${ }^{2}$, Maciej Sosna ${ }^{1,3}$, John R. Owen*,1 \\ Chemistry, University of Southampton, SO17 1BJ, Southampton, UK
}

\section{A R T I C L E I N F O}

\section{Article history:}

Received 18 December 2012

Received in revised form 5 February 2013

Accepted 9 February 2013

Available online 26 February 2013

\section{Keywords:}

Superoxide

Electrodeposition

Electropolymerisation

Polymer electrolyte

$3 \mathrm{D}$ microbattery

\begin{abstract}
A B S T R A C T
Poly(acrylonitrile) films were deposited electrochemically onto vitreous carbon electrodes from airsaturated acrylonitrile. Electrodeposition on gold was investigated with the use of an electrochemical quartz crystal microbalance (EQCM). It was found that the onset of deposition coincided with the reduction of dissolved oxygen at the electrode surface, indicating that the polymerisation reaction is initiated by the nucleophilic superoxide anion. The chemical composition of the film was confirmed by Raman spectroscopy. Such electrodeposited polymer films may have applications as polymer electrolytes for 3D microbattery applications.
\end{abstract}

(c) 2013 Elsevier Ltd. All rights reserved.

\section{Introduction}

The current expansion in the demand for energy storage devices has created a need for batteries and supercapacitors of arbitrary shape and the ability to place the device in otherwise unused space. There is also much interest in increasing the volumetric power density of storage devices by depositing the cell laminate, layer by layer, on a porous substrate of high internal area, thereby reducing the distance that ions have to travel between the electrodes during discharge. A key technology that is required here is the conformal deposition of a pinhole-free polymer electrolyte.

In this work, electrodeposition was investigated as a method of depositing the electrolyte as a critical step in the fabrication of a 3D microbattery (depicted in Fig. 1) by successive deposition of base electrode (e.g. anode of a lithium ion battery), electrolyte and top electrode (e.g. cathode) layers as described in the recent review by Roberts et al. [1]. The electrolyte in this case is an inert polymer that is permeable to, and swelled with an organic electrolyte solution. The aim of the present study was to demonstrate the feasibility of depositing a suitable polymer onto an electronically conducting substrate as a uniform layer up to a few micrometers in thick-

\footnotetext{
* Corresponding author. Tel.: +44 238059 2184; fax: +44 2380593781 .

E-mail address: jro@soton.ac.uk (J.R. Owen).

1 ISE Member.

2 Present address: Department of Chemistry - Ångström, Box 538, Lägerhyddsvägen 1, SE-75121 Uppsala, Sweden.

3 Present address: Interdisciplinary Nanoscience Center (iNANO), Aarhus University, Gustav Wieds Vej 14, DK-8000, Aarhus, Denmark.
}

ness. The precursor monomer was contained in the electrolyte, and the substrate was used as the negative electrode as in a standard electroplating process where the thickness is controlled according to the amount of charge passed through a cell. The principle of the method, however, cannot be regarded as the normal faradaic electroplating process because the electrically insulating product would limit the growth to a few monolayers. Instead, the principle of electropolymerisation was used, as developed by several groups $[2,3]$.

It is generally recognised that the $\mathrm{O}_{2} / \mathrm{O}_{2}{ }^{-}$redox couple is quasi-reversible in aprotic solvents such as acetonitrile, where the superoxide radical anion has a half-life of approximately $40 \mathrm{~min}$ at room temperature in the presence of tetraalkylammonium cations [4-6]. $\mathrm{O}_{2} / \mathrm{O}_{2}{ }^{-}$is a moderately strong nucleophile which reacts with sufficiently active Michael acceptors (e.g., vinyl groups with an electron-withdrawing substituent, such as acrylonitrile). Indeed, the use of electrogenerated superoxide as a nucleophile in organic synthesis is reported in the literature [7], as is the use of $\mathrm{KO}_{2}$ as an initiator for the polymerisation of a range of vinyl monomers [8].

The electrochemical quartz crystal microbalance (EQCM) is a useful tool for monitoring the deposition of a thin film at an electrode surface, where apparent mass changes [9-11] at the electrode can be recorded in situ and correlated with the electrochemical response. Such measurements can also determine the current efficiency by measuring the ratio of mass deposited at the electrode to the total charge passed. Similar studies on the electrografting (i.e., covalent attachment of a polymer to a surface) of acrylonitrile and methacrylonitrile have previously been reported in the literature [12,13]. 


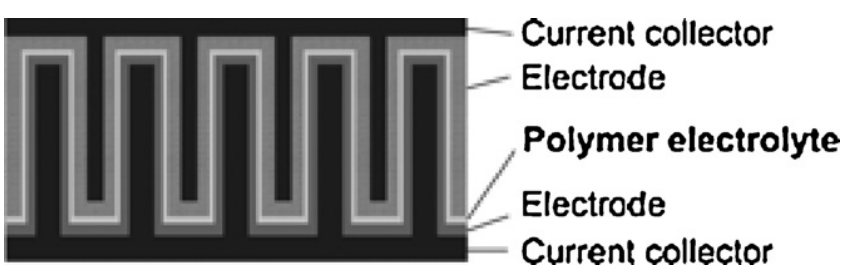

Fig. 1. Schematic diagram of an example 3D microbattery architecture.

\section{Experimental}

Acrylonitrile (AN, Aldrich) was distilled over $\mathrm{CaH}_{2}$ prior to use. Tetrabutylammonium perchlorate (TBAP, Aldrich) was dried at $120^{\circ} \mathrm{C}$ under vacuum overnight prior to use. Electrodeposition experiments were performed using a versatile multichannel potentiostat (VMP2, Princeton Applied Research - Bio-Logic Science Instruments). The reference electrodes were prepared by dipping a silver wire into a solution of $10 \mathrm{mM} \mathrm{AgNO}_{3}$ or $\mathrm{AgClO}_{4}$ and $50 \mathrm{mM}$ TBAP in ACN, and were connected to the cell via a glass frit.

Poly(acrylonitrile) (PAN) was deposited by cyclic voltammetry from air-saturated acrylonitrile containing $50 \mathrm{mM}$ TBAP as supporting electrolyte over 5 cycles between $-0.5 \mathrm{~V}$ and $-3.0 \mathrm{~V}$ vs $\mathrm{Ag} / \mathrm{AgNO}_{3}$ at a scan rate of $50 \mathrm{mV} \mathrm{s}^{-1}$. The working electrodes used were $3 \mathrm{~mm}$ diameter glassy carbon and Pt gauze was used as the counter electrode. Raman spectra were recorded using a Renishaw Raman 2000 system with a $633 \mathrm{~nm}$ HeNe laser at $2.2 \mathrm{~mW}$, using two $30 \mathrm{~s}$ accumulations, recorded in extended mode. The spot size was $5 \mu \mathrm{m}$ ( $\times 50$ objective).

EQCM experiments were carried out using a $\mu$ Autolab type III potentiostat interfaced with a QCM200 quartz crystal microbalance system (Stanford Research Systems). PAN was deposited onto the $1.37 \mathrm{~cm}^{2}$ gold working electrode of a 1 inch diameter, $5 \mathrm{MHz}$ AT-cut quartz crystal substrate (Stanford Research Systems). The electrochemical substrate was set up in a standard three-electrode configuration with a $\mathrm{Ag} / \mathrm{AgClO}_{4}$ reference electrode and a Pt gauze counter electrode.

\section{Results and discussion}

Fig. 2 shows the cyclic voltammetry of air-saturated acrylonitrile. The first cycle shows a single reduction peak at approximately $-1.3 \mathrm{~V}$ vs $\mathrm{Ag} / \mathrm{AgNO}_{3}$, corresponding to the reduction of oxygen to superoxide. This peak rapidly decays to zero current, indicating passivation of the electrode. Negligible current is passed on the reverse scan or any subsequent cycles, and no other reduction processes are observed. This is in contrast to the electrochemistry of the same system in the absence of oxygen, where the reduction of acrylonitrile itself close to $-3.0 \mathrm{~V}$ vs $\mathrm{Ag} / \mathrm{AgNO}_{3}$ is observed, as described in the literature [3].

After removing the electrode from the solution, a white film is clearly visible on the electrode surface. On heating to $\sim 150^{\circ} \mathrm{C}$, the film softens and becomes transparent ( $T_{g}$ for amorphous PAN is $\sim 85^{\circ} \mathrm{C}[14]$ ). The Raman spectrum for this film is given in Fig. 3 and shows peaks at 2940 (alkyl C-H) and $2244 \mathrm{~cm}^{-1}(\mathrm{C} \equiv \mathrm{N})$, consistent with the formation of PAN as expected from a vinyl polymerization of the given monomer. Smaller peaks at lower wavenumbers are likely to be due to impurities; for example, the peak at $1450 \mathrm{~cm}^{-1}$

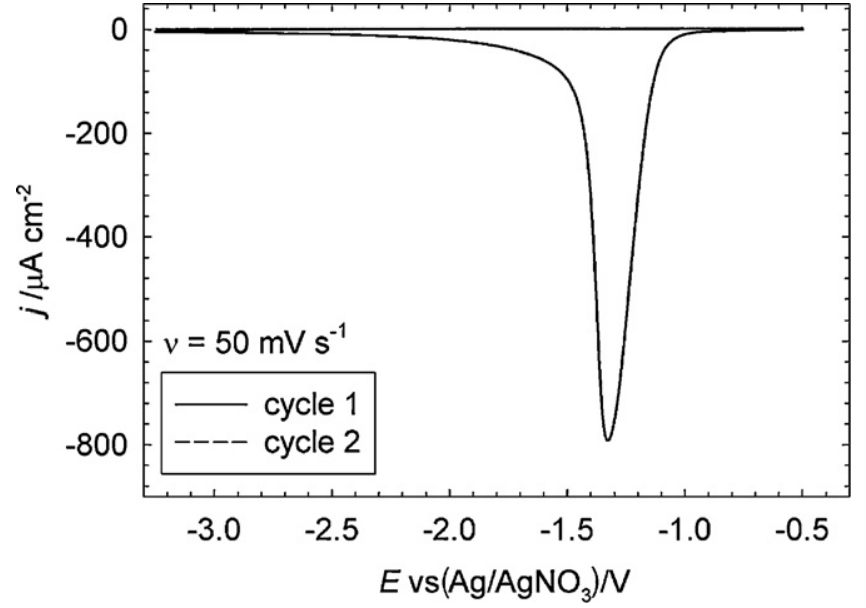

Fig. 2. Cyclic voltammograms for oxygen on a $3 \mathrm{~mm}$ diameter glassy carbon disc electrode in air-saturated acrylonitrile containing $50 \mathrm{mM}$ TBAP as supporting electrolyte at a scan rate of $50 \mathrm{mV} \mathrm{s}^{-1}$

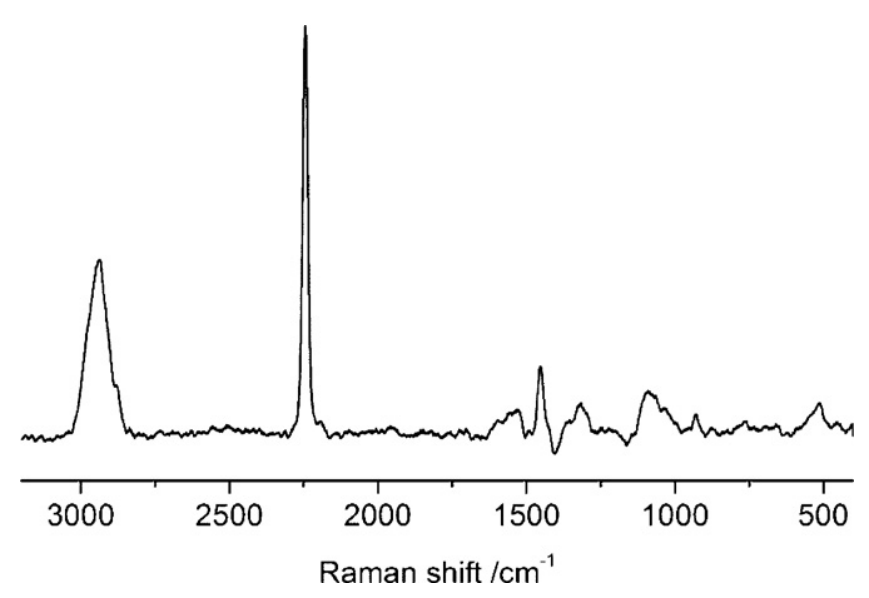

Fig. 3. Raman spectrum for a PAN film deposited from air-saturated AN containing $50 \mathrm{mM}$ TBAP on $3 \mathrm{~mm}$ diameter glassy carbon over 5 cycles at a scan rate of $50 \mathrm{mV} \mathrm{s}^{-1}$.

is consistent with a fused ring structure formed from a polymerisation of the nitrile groups as a consequence of an anionic polymerisation mechanism [15].

A probable reaction mechanism for the electropolymerisation is suggested in Fig. 4, starting with a highly reactive radical product of nucleophilic addition of superoxide to acrylonitrile which initiates the polymerisation, in a similar mechanism to that previously established in the literature for the electropolymerisation of acrylonitrile; i.e., where radicals and/or radical anions at a high concentration near the electrode surface dimerise, and the polymerisation reaction then proceeds primarily through an anionic mechanism [16].

Films deposited on glassy carbon were imaged using an optical profilometer. Fig. 5 shows a 3D reconstruction of the surface of a PAN film deposited under the conditions already described. The images show a cracked surface, probably as a result of solvent drying following the deposition. From the 3D reconstruction, we

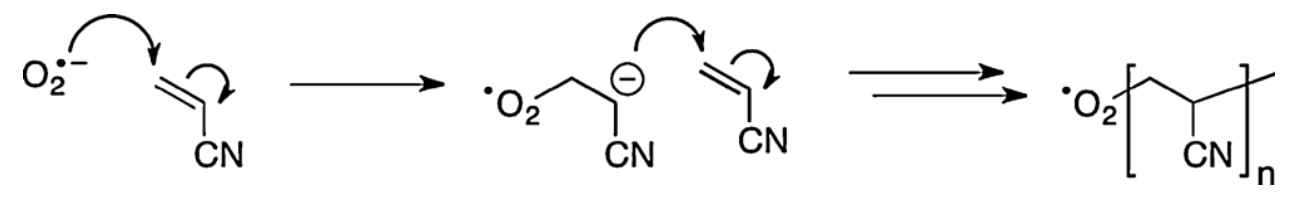

Fig. 4. Suggested reaction scheme for the polymerisation of acrylonitrile by electrogenerated superoxide anions. 

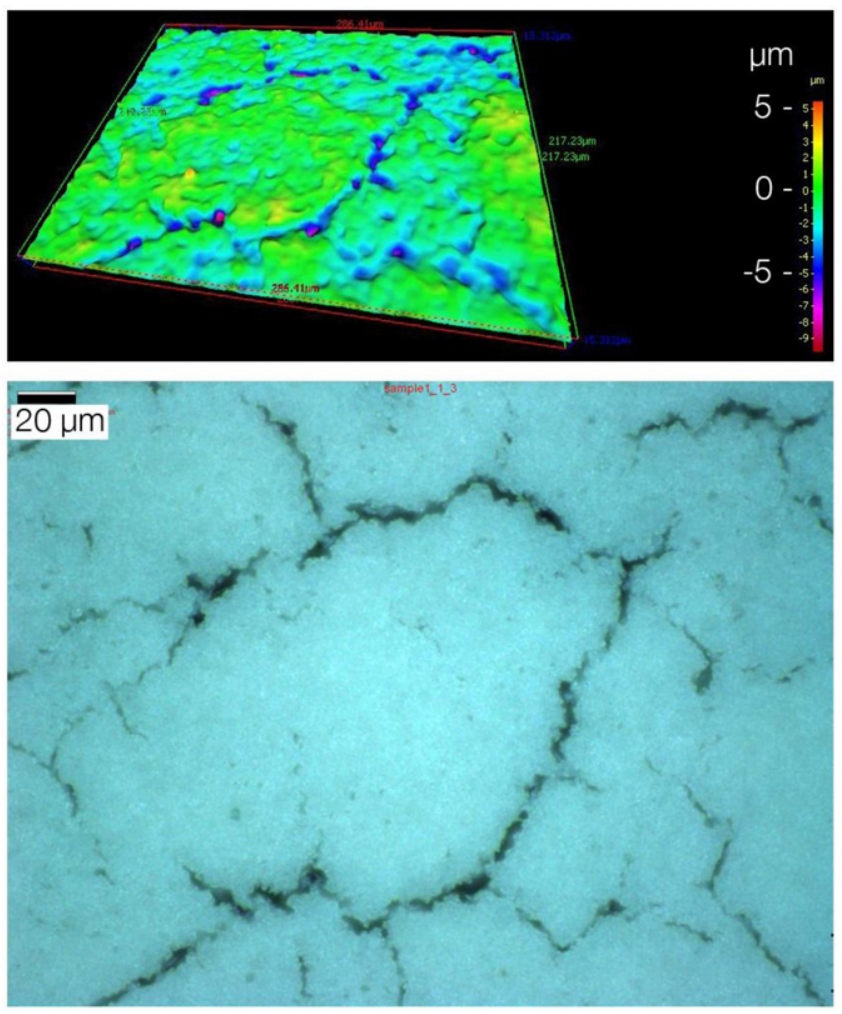

Fig. 5. 2D and 3D images of the electrodeposited PAN film with $50 \times$ magnification.

can estimate the depth of the cracks as approximately $5 \mu \mathrm{m}$. The film thickness was determined by scratching the film to expose the glassy carbon surface, revealing a film thickness of approximately $20 \mu \mathrm{m}$. The average areal roughness for non-cracked regions in the sample was found to range from $200 \mathrm{~nm}$ to $400 \mathrm{~nm}$, indicating a relatively uniform deposition.

Fig. 6 shows the cyclic voltammetry and the apparent mass change as measured by the EQCM for the first cycle of the deposition at a gold disc electrode. The frequency change output by the EQCM has been converted to an apparent mass change according to Sauer-

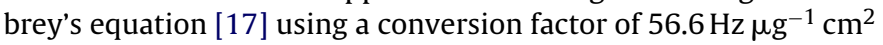
for the crystals used in this experiment, assuming that the deposit is a uniform, rigid mass. Of course, the deposit is neither truly uniform nor is it expected to be rigid, so the true mass will differ from

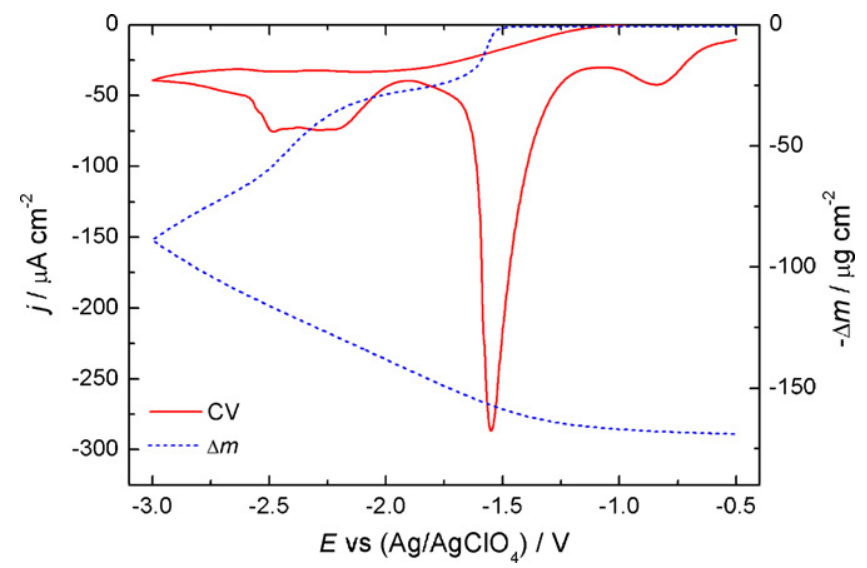

Fig. 6. Cyclic voltammetry and mass change from EQCM for the first cycle of acrylonitrile containing $50 \mathrm{mM}$ TBAP on a $1.37 \mathrm{~cm}^{2}$ gold disc electrode at a scan rate of $50 \mathrm{mV} \mathrm{s}^{-1}$.

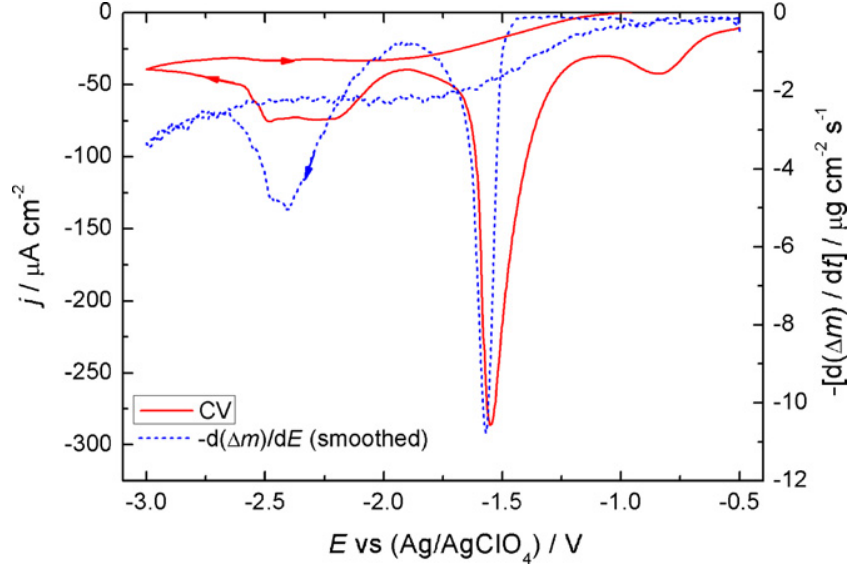

Fig. 7. Cyclic voltammetry and first order derivative of mass change from EQCM for the first cycle of acrylonitrile containing $50 \mathrm{mM}$ TBAP on a $1.37 \mathrm{~cm}^{2}$ gold disc electrode at a scan rate of $50 \mathrm{mV} \mathrm{s}^{-1}$.

the values calculated here. However, such values can still serve as a useful estimate.

The voltammetry on gold as shown in Fig. 6 is more complex than the previous voltammetry on glassy carbon shown in Fig. 2. In particular, the peak at $-0.8 \mathrm{~V} \mathrm{vs} \mathrm{Ag} / \mathrm{AgClO}_{4}$ is of unknown origin but may be related to trace water in the electrolyte. However, the most prominent feature of the voltammogram is still the large reduction peak at $-1.6 \mathrm{~V}$ vs Ag/ $/ \mathrm{AgClO}_{4}$ which corresponds to the reduction of oxygen to superoxide. The reduction peak coincides with a sharp decrease in the quartz crystal resonant frequency, indicating precipitation of the polymer on the electrode surface. Furthermore, this confirms that the polymerisation reaction is initiated by the generation of superoxide. The mass of the polymer increases gradually through the rest of the cycle, with the rate of increase in mass slowing as the production of $\mathrm{O}_{2}{ }^{-}$ceases. At the end of the first cycle, the mass of the polymer on the electrode surface is given by Sauerbrey's equation as $169 \mu \mathrm{g} \mathrm{cm}^{-2}$. Assuming a density of the order of $1 \mathrm{~g} \mathrm{~cm}^{-3}$, we can estimate a film thickness in the range $1-2 \mu \mathrm{m}$.

Because cyclic voltammetry imposes a linear change in potential with time, the rate of film growth, expressed as the derivative of mass with respect to time, as shown in Fig. 7, is proportional to the derivative with respect to potential. The plot of $d(\Delta m) / d t$ has been smoothed using an adjacent averaging algorithm in order to reduce the large amount of noise as a result of noise in the original data. From Fig. 7, it can be seen that there is negligible mass change before the peak at $-1.6 \mathrm{~V} \mathrm{vs} \mathrm{Ag} / \mathrm{AgClO}$, where there is a sharp peak in the rate of change of mass. There is a delay between the start of the oxygen reduction peak in the voltammetry at $-1.13 \mathrm{~V} \mathrm{vs} \mathrm{Ag} / \mathrm{AgClO}{ }_{4}$ and the onset of deposition at $-1.43 \mathrm{~V} \mathrm{vs} \mathrm{Ag} / \mathrm{AgClO}$. At $50 \mathrm{mV} \mathrm{s}^{-1}$, this delay is equivalent to six seconds, and could be interpreted as a nucleation step, where oligomers are formed in solution and aggregate before deposition at the electrode surface. The coincidence of the voltammetric peak and the peak in the rate of change of mass after $-1.43 \mathrm{~V}$ vs $\mathrm{Ag} / \mathrm{AgClO}_{4}$ indicates a good correlation between the rate of change of mass and the rate of formation of superoxide. The latter is in turn determined by the applied potential before the peak and by the rate of oxygen diffusion from the solution (air-saturated at $\sim 1 \mathrm{mM}$ ) after the peak, when diffusion is slowed down by the deposited film. Accordingly, this indicates that electrochemistry can provide a level of control over film thickness.

There is a further increase in the rate of change of mass peaking at approximately $-2.5 \mathrm{~V} \mathrm{vs} \mathrm{Ag} / \mathrm{AgClO}$; that is, occurring at the potential at which reduction of acrylonitrile would be expected to be observed. Indeed, it is the reduction of the vinyl group to form the radical anion which is the accepted mechanism for the electropolymerisation of vinyl monomers in aprotic solvents $[3,16]$. 


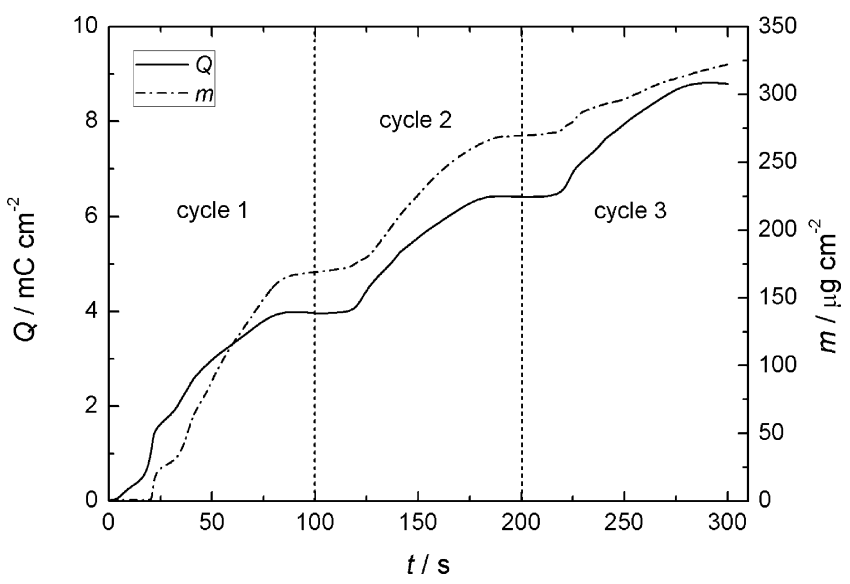

Fig. 8. Charge and film mass versus time for the first three cycles of the electrodeposition of PAN from AN containing $50 \mathrm{mM}$ TBAP on a $1.37 \mathrm{~cm}^{2}$ gold disc at a scan rate of $50 \mathrm{mV} \mathrm{s}^{-1}$.

Table 1

Average faradaic yield per cycle.

\begin{tabular}{llll}
\hline Cycle number & $m / \mu \mathrm{g} \mathrm{cm}^{-2}$ & $\mathrm{Q} / \mathrm{mC} \mathrm{cm}^{-2}$ & $n$ \\
\hline 1 & 168.9 & 3.96 & 77.6 \\
2 & 100.6 & 2.45 & 74.7 \\
3 & 52.5 & 2.39 & 40.0 \\
\hline
\end{tabular}

The increase in the rate of deposition between -2.7 and $-3.0 \mathrm{~V}$ vs $\mathrm{Ag} / \mathrm{AgClO}_{4}$ and the simultaneous decrease of current indicates passivation of the electrode surface. On the reverse scan, the flat profile of the rate of mass change curve in the region between $-2.5 \mathrm{~V}$ and $-1.75 \mathrm{~V}$ vs $\mathrm{Ag} / \mathrm{AgClO}_{4}$ indicates a constant rate of deposition.

The QCM is able to follow three voltammetric cycles before the mass change becomes too large and the crystal essentially saturates. The charge passed and the apparent mass change over these three cycles is shown in Fig. 8. The plot shows a decrease in the charge passed and a more pronounced decrease in the rate of mass increase with increasing cycle number, indicating selflimiting growth and a decreasing yield $n$, which is here defined as ratio of the number of moles of acrylonitrile deposited to the number of moles of electrons passed. This can be determined on a per cycle basis from the following equation:

$n=\frac{m z F}{M_{r} Q}$

where the number of electrons, $z$, for any electron transfer reaction during the deposition, is 1.

The values for the average faradaic yield per cycle are tabulated in Table 1. The overall faradaic yield is similar for both first and second cycles and is calculated to be between 70 and 80 . This suggests that the apparent mass increases are indicative of the deposition rate and that the faradaic yield can be interpreted, for example, as a PAN chain with an average length of 75 monomer units being formed from each initiator electron. The apparent faradaic yield drops to 40.0 by the end of the third cycle. This may be, in part, due to the failure of the Sauerbrey equation as a thicker, less rigid, film is deposited. Overall, the large values are in stark contrast to equivalent values of between 0.4 and 2 as measured for the deposition of PAN on glassy carbon under identical conditions from solutions of $2 \mathrm{M}$ acrylonitrile in acetonitrile, as we have previously reported [18]. The higher faradaic yield here is a reflection of the higher concentration of acrylonitrile ( $100 \% \mathrm{AN}$ is at a $15.3 \mathrm{M}$ concentration), hence faster propagation kinetics, as well as a lower solubility of PAN in AN compared to acetonitrile.

\section{Conclusions}

The superoxide anion, generated in situ by reduction of dissolved oxygen, was found to initiate the electrodeposition of poly(acrylonitrile) from pure acrylonitrile, which can also act as a solvent during the polymerisation. This method is particularly suitable for coating a battery electrode material because it employs milder electrode potentials than required for direct reduction of the monomer $\left(-2.5 \mathrm{~V}\right.$ vs. $\mathrm{Ag} / \mathrm{AgClO}_{4}$, which is equivalent to about $0.5 \mathrm{~V}$ vs. $\mathrm{Li}$, at which potential transition metal oxide cathode materials are reduced to the metals in the presence of lithium ions). The method was found to rapidly deposit uniform thin films characteristic of poly(acrylonitrile), as characterised by Raman spectroscopy and optical profilometry. EQCM revealed evidence of self-limiting growth and a good correlation between the rate of deposition and the passage of voltammetric current, indicating control over the electrodeposition, despite a non-faradaic reaction with faradaic yields in excess of 70 monomer units per Faraday.

\section{Acknowledgements}

The authors wish to thank Dr Jurgita Zekonyte of the national Centre for Advanced Tribology at Southampton (nCATS) for the optical profilometer images, Professor Phil Bartlett for useful discussions and to EU FP7 NMP "SUPERLION" and EPSRC DTA for funding.

\section{References}

[1] M.R. Roberts, P.A. Johns, J.R. Owen, D. Brandell, K. Edström, G. El-Enany, C. Guery, D. Golodnitsky, M.J. Lacey, C. Lecoeur, H. Mazor, E. Peled, E. Perre, M.M. Shaijumon, P. Simon, P.-L. Taberna, 3D lithium ion batteries-from fundamentals to fabrication, Journal of Materials Chemistry 21 (2011) 9876.

[2] G. Lécayon, Y. Bouizem, C. Legressus, C. Reynaud, C. Boiziau, C. Juret, Grafting and growing mechanisms of polymerized organic films onto metallic surfaces, Chemical Physics Letters 91 (1982) 506.

[3] S. Gabriel, R. Jérôme, C. Jérôme, Cathodic electrografting of acrylics: From fundamentals to functional coatings, Progress in Polymer Science 35 (2010) 113.

[4] H. Lund, O. Hammerich, Organic Electrochemistry: Fourth Edition, Revised and Expanded, Marcel Dekker, Inc, New York, 2001.

[5] D. Vasudevan, H. Wendt, Electroreduction of oxygen in aprotic media, Journal of Electroanalytical Chemistry 392 (1995) 69.

[6] C.M. Ó’Laoire, S. Mukerjee, K.M. Abraham, E.J. Plichta, M.A. Hendrickson, Hendrickson, Influence of Nonaqueous Solvents on the Electrochemistry of Oxygen in the Rechargeable Lithium-Air Battery, Journal of Physical Chemistry C 114 (2010) 9178

[7] R. Dietz, A.E.J. Forno, B.E. Larcombe, M.E. Peover, Nucleophilic Reactions of Electrogenerated Superoxide Ion, Journal of the Chemical Society (B) (1970) 816.

[8] Y.K. Han, J.H. Kim, S.K. Choi, Polymerisation of vinyl monomers initiated by $\mathrm{KO}_{2}-$ charge transfer agent systems. II, Journal of Polymer Science Part A: Polymer Chemistry 29 (1991) 281.

[9] M. Hepel (Ed.), Interfacial Electrochemistry. Theory, Experiment and Applications, Marcel Dekker, Inc, New York, 1999, p. 599.

[10] M. Stobiecka, M. Hepel, J. Radecki, Transient conformation changes of albumin adsorbed on gold piezoelectrodes, Electrochimica Acta 50 (2005) 4873.

[11] M. Hepel, E. Cateforis, Studies of copper corrosion inhibition using electrochemical quartz crystal nanobalance and quartz crystal immittance techniques, Electrochimica Acta 46 (2001) 3801.

[12] J. Charlier, C. Bureau, G. Lécayon, Electropolymerization of methacrylonitrile and N-vinyl-2-pyrrolidone as probed by an EQCM, Journal of Electroanalytical Chemistry 465 (1999) 200.

[13] J. Tanguy, On the electropolymerization of methacrylonitrile and acrylonitrile as studied by CV, EQCM and EIS, Journal of Electroanalytical Chemistry 487 (2000) 120.

[14] J.E. Mark (Ed.), Polymer Data Handbook, Oxford University Press, Oxford, 1999.

[15] F. Beck, Electrodeposition of polymer coatings, Electrochimica Acta 33 (1988) 839.

[16] C. Bureau, Polymerization reaction coupled to charge transfer: propagation versus termination as a source of permanent travelling waves and multi-peak voltammograms, Journal of Electroanalytical Chemistry 479 (1999) 43.

[17] G. Sauerbrey, Verwendung von Schwingquarzen zur Wägung dünner Schichten und zur Mikrowägung, Zeitschrift Für Physik 155 (1959) 206.

[18] G. El-Enany, M.J. Lacey, P.A. Johns, J.R. Owen, Owen, In situ growth of polymer electrolytes on lithium ion electrode surfaces, Electrochemistry Communications 11 (2009) 2320. 